\title{
Editorial \\ Comments on 22 years of editing
}

The first issue of this Journal was published in September 1968. Before that, in 1967, after the decision to publish with Psychonomic Journals had been made, Clifford Morgan and I held several discussions in which, among other things, we considered names for the new journal. Among them were Experimental Methods and Instrumentation in Psychology, the title of a relatively successful book at the time (Sidowski, 1966), and Behavioral Research Methodology; we finally settled on Behavior Research Methods \& Instrumentation (BRMI).

A more difficult decision concerned publication frequency. The proposed content of the Journal was so different from that of other journals in the behavioral sciences that it was difficult to predict success or failure and/or the number of manuscripts that might be submitted (indeed, 3 of the original 10 consulting editors who had agreed to help predicted a very early failure). Nevertheless, we finally decided on bimonthly publication.

Although, from the first issue on, the Journal contained a section on Computer Technology, it was not until 1984 that the Journal name was lengthened to Behavior Research Methods, Instruments, \& Computers (BRMIC). The delay was due primarily to the belief that computers were research instruments and therefore that adding the word computers was unnecessary. However, the accelerated use of microcomputers and the sudden and frequent appearances of new computer journals or computer sections in other journals in the behavioral sciences now mandated the addition. BRMI was no longer the only house of its type on the block. Indeed, section titles that had originated with BRMI were being duplicated in several other journals. Historically, Behavioral Science had published manuscripts on Computers in Behavioral Science as well as Computer Program Abstracts years before this Journal originated, but the emphasis was not on laboratory computers as it was to be in BRMI(C). Of course, minicomputers were not in great supply in the early 1960 s, and the influence of micros was yet to come.

In 1973, a section on Computer Program Abstracts/Algorithms was added to BRMI. And in 1974, Steven G. Vandenberg joined BRMI as a consulting editor for the section after having served in the same capacity for Behavioral Science, whose staff had decided to stop publishing the material.

The original group of BRMI Consulting Editors consisted of M. E. Bitterman, J. V. Brady, Clinton Brown, Judson Brown, David A. Grant, Paul Hasler, James McGaugh, John Platt, Manuel J. Smith, and William R. Uttal. Norman H. Anderson and Marshall $H$. Haith were added in 1969. Given the state of experimental psychol- ogy at the time, all were selected to provide quality editorial guidance for the areas covered. The list changed through the years to reflect the changing nature of methodology, instrumentation, and computer technology. It is the time and effort given by these Consulting Editors and other consultants that made the Journal. The names of the Consulting Editors that appeared in the masthead from 1968 to 1989 are:

$\begin{array}{ll}\text { D. Aaronson } & \text { N. H. Anderson } \\ \text { R. Bakeman } & \text { W. R. Biersdorf } \\ \text { M. E. Bitterman } & \text { J. V. Brady } \\ \text { F. B. Bremner } & \text { C. Brown } \\ \text { J. Brown } & \text { C. L. Cunningham } \\ \text { D. A. Dewsbury } & \text { D. Diener } \\ \text { W. P. Dunlap } & \text { D. Eckerman } \\ \text { D. A. Grant } & \text { B. F. Green } \\ \text { W. Greene } & \text { M. H. Haith } \\ \text { P. Hasler } & \text { J. J. Johnson } \\ \text { H. L. Kaplan } & \text { D. T. Krausman } \\ \text { R. S. Lehman } & \text { A. M. Lesgold } \\ \text { C. M. Levy } & \text { J. McGaugh } \\ \text { R. A. Monty } & \text { M. M. Patterson } \\ \text { J. W. Pellegrino } & \text { J. Platt } \\ \text { A. V. Reed } & \text { J. D. Rugh } \\ \text { G. P. Sackett } & \text { M. J. Smith } \\ \text { D. I. Tepas } & \text { W. R. Uttal } \\ \text { L. Wood } & \text { W. T. Woodard }\end{array}$

During the first year of publication, two issues of BRMI, totaling 98 pages, were printed; the first full year (1969) yielded 234 pages. The total number of pages for 1988 was 589 . Rejections consistently have averaged about $50 \%$ per year.

The original Editorial policy statement and Instructions for Contributors are duplicated on page 567 . Because a number of statistical manuscripts had been submitted, the question of whether or not to publish such submissions arose several times over the years. Generally, however, since most statistical papers were published in the Psychological Bulletin or established statistical journals, the quality of most of the papers received was poor or marginal. (It seemed to be that whenever an article that appeared to be even slightly related to the area of statistics was published in BRMI(C), all of the old rejects were taken out of drawers and files and submitted to the Editor "to give it a try." The best of those were the ones with newly retyped cover pages. The most impressive were the manuscripts (in any area) individually encased in plastic jackets, each copy (three or four) inserted into a separate manila envelope, all-along with a proper/mannerly cover letter-put into a larger envelope, 
which was then sent by express mail in the special envelope supplied by the express company!)

Occasionally, special sections devoted to specific topics of current concern were included in regular issues of BRMI(C). Bert Green organized a collection of nine manuscripts on Computer-Based Tachistoscopes (1978, Vol. 10, pp. 754-795); John Rugh organized 11 manuscripts on Biofeedback Instrumentation (1978, Vol. 10, pp. 595-665). There were also several special entire issues of the Journal dedicated to various topics, among them: Computer Technology and Methodology in Clinical Psychology, Psychiatry, and Behavioral Medicine, coedited by James J. Johnson (1981, Vol. 13, pp. 389-636); Computers in Vision Research, William Uttal (1978, Vol. 18, pp. 483-644); and Microprocessors and Microcomputers, Joseph Sidowski (1978, Vol. 10, pp. 463-593). The entire December 1987 issue was devoted to Computer Technology: Index to Articles in BRMIC 1977-1987, coedited by Gwendolyn E. Campbell (Vol. 19, pp. 487-561).

Since 1974, the Proceedings of the National Conference on the Use of On-Line Computers in Psychology (now the Society for Computers in Psychology) have been published annually in BRMI(C) and have had significant influence.

The trend away from "basic instrumentation" has accelerated noticeably, and manuscripts describing various noncomputer hard-wired laboratory circuits have dwindied. During the very early years of the Journal, articles on instrumentation and laboratory techniques were of interest and plentiful, resulting in the need for reviewers knowledgeable in circuitry and gadgetry. That is no longer the case. Now it is computer hardware and software, although a manuscript describing methodology almost as primitive as that of hammering the old-time phonograph needles through the skull to serve as electrodes is occasionally received.

In the early 1960 s, there were few laboratory computer systems, especially those of the on-line real-time variety. Most of the systems used in the behavioral sciences were of the types described by Borko (1962), Green (1963), and Newell and Simon (1963). In 1963, psychologists Donald Blough, Alan Boneau, and Bernard Weiss participated in a sponsored program to determine whether or not the LINC $2 \mathrm{~K}$ memory computer could be integrated into research laboratories. The few papers available on laboratory systems were published in the Proceedings of the Digital Equipment Computer Users Society (DECUS). Uttal's book on techniques for applying real-time computers in the laboratory was published in 1968; it was followed by the Weiss volume in 1973 .

Since its inception, BRMI(C) has been dedicated to the idea of enhancing the knowledge and/or interest of psychologists in the possible applications and uses of computers in laboratories. It took little foresight to appreciate their future potential. The Journal was also meant to serve as a publication outlet for experienced users who might otherwise have difficulty communicating their knowledge. With BRMI(C) available for publishing computer articles, it was anticipated that (1) information exchange would be stimulated, (2) the purchases and applications of laboratory computers would accelerate, and (3) in the process, the interest and involvement of students would be stimulated to the extent that some would subsequently develop their own systems. With the organization of the National Conference on the Use of On-Line Computers in Psychology in 1971, a supportive boost was given to the original goals. In the beginning, though, to encourage computer users to write, permission was obtained from the Digital Equipment Corporation (suppliers of the popular PDP series of computers) to reprint appropriate DECUS articles in BRMI. In addition, some articles were solicited.

In an early survey of computer usage (1967), Vandenberg, Green, and Wrigley reported that 237 staff members and 397 graduate students in 109 psychology departments had had "some experience" with computers. The same study reported that for the entire calendar year of 1960 , psychology departments used an average of 75.4 hours of machine time. Of course, the systems were of the IBM 650, UNIVAC, and IBM 704 vintage.

In 1972, a computer-use survey (Sidowski, 1972) reported that only 11 authors provided $52 \%$ of the citations that reflected uses of laboratory computers as research tools. In 1970, of the more than 275 articles published in the Journal of Comparative and Physiological Psychology (JCPP), only 2 reported the use of a computer-an IBM 360, for EEG spectral analysis, and a CAT signal averager. Over the same 6-year period, $1 \%$ of the approximately 1,900 articles published in the Journal of Experimental Psychology reported the use of computers. In 1974, it was about 5\% (Sidowski, 1976).

It is obvious that the introduction of microcomputers in the 1970 s changed the laboratory applications tremendously. In terms of articles published in BRMI(C), computer hardware and software became a major focus. Initially, hardware was emphasized, but soon software became the major point of interest. Some applications, however, have raised questions of concern, as was the case with minicomputers. Uttal (1968) emphasized the importance of the real-time contingent capabilities of the laboratory computer. In 1971-1972, he emphasized the ability of the laboratory computer to open new theoretical and empirical doors, and to provide new techniques for the analysis of problems that could not have been handled previously. Several years later, Uttal indicated that after a decade of laboratory-computer use, contingent procedures were not so influential. Apparently this was because the statistical techniques and reporting procedures were not well enough developed to handle contingent results, and users reverted to using more conventional procedures (see Sidowski, 1976). Donald Norman expressed the same sentiments in an address given to the National Conference on the Use of On-Line Computers 
in Psychology in 1973. And a few weeks ago, I heard three very respectable computer-experienced psychologists express the same concern.

Researchers and students generally refer to journals in order to study the results of experiments. But data are only as good as the experimental design, the methodology, and the quality and reliability of the instrumentsincluding microcomputers-used. In his Nobel prize address, "Some effects of disconnecting the cerebral hemispheres," Roger W. Sperry (1982) stressed this fact when he referred to a simple technique for lateralizing visual input, which he and Jay Myers described in an ar- ticle published in BRMI (Myers \& Sperry, 1982). Of the 138 Nobel laureates in physics and chemistry from 1901 through 1960, 112 were accorded this high honor for research in which instruments were dominant (Sidowski \& Ross, 1969, p. 187).

The 22 years during which I have edited BRMI(C) have been interesting, gratifying, and enjoyable. I am, needless to say, pleased not only that it has survived, but also that it has made a contribution to the field of behavioral research.

Joseph B. Sidowski

\section{REFERENCES}

BoRKo, H. (Ed.) (1962). Computer applications in the behavioral sciences. Englewood Cliffs, NJ: Prentice-Hall.

GreEN, B. F., JR. (I963). Digital computers in research: An introduction for behavioral and social scientists. New York: McGraw-Hill. Newell, A., \& Simon, H. A. (1963). Computers in psychology. In R. D. Luce, R. Bush, \& E. Galanter (Eds.), Handbook of mathematical psychology, I. New York: Wiley.

MYers, J. J., \& SPERRY, R. W. (1982). A simple technique for lateralizing visual input that allows prolonged viewing. Behavior Research Methods \& Instruments, 14, 305-308.

SiDowsk, J. B. (1966). Experimental methods and instrumentation in psychology. New York: McGraw-Hill.

SIDOWSKI, J.B. (1972). Various uses of minicomputers in psychology. Behavior Research Methods \& Instrumentation, 4, 43-50.
Sidowsku, J. B. (1976). On-line instrumentation in psychology: Dildo or the real thing? Behavior Research Methods \& Instrumentation2, 8, 52-56.

Sidowsk, J. B., \& Ross, S. (1969). Special issue: Instrumentation in psychology. American Psychologist, 24, 187-403.

SPERRY, R. (1982). Some effects of disconnecting the cerebral hemispheres. Science, 217, 1223-1226.

UTTAL, W. R. (1968). Real time computers: Techniques and aplications in the psychological sciences. New York: Harper \& Row.

VandenberG, S. G., Green, B. G., Wrigley, C. F. (1962). A survey of computer usage in departments of psychology and sociology. Behavioral Science, 7, 108-110.

WEIss, B. (Ed.) (1973). Digital computers in the behavioral laboratory. New York: Appleton-Century-Crofts.

\section{EDITORIAL}

Behavior Research Methods and Instrumentation is a bimonthly publication that will publish articles covering experimental methods and designs, instrumentation and laboratory techniques, and computer technology. Articles specifically dealing with statistics will not be published. Comparisons of methods and/or instruments are invited, as are papers concerned with experimental controls. Reports of experiments are inappropriate except in support of method or instrument evaluations; in most cases, authors describing devices or techniques will be expected to provide supportive data. Innovations and extensions of existing methods or instruments should be covered briefly and concisely with adequate reference to the original work(s).

Since the fields of instrumentation and computer technology are vast and diverse, and the daily work of the behavioral scientist often requires technical ability beyond the scope of any single academic discipline, articles and briefs intended to bridge technical disciplines are welcome from whatever source. In support of the above, editorial policy will be as flexible as possible.

An editorial PRINTOUT will appear in each issue and provide information on products, new instrumentation, technological developments, abbreviated buyer's guides, and other items of interest.

Future issues of this journal will carry advertising of apparatus and other products useful to research workers in psychology and behavioral sciences.

\section{INSTRUCTIONS FOR CONTRIBUTORS}

Individuals contemplating publication should heed the pleas of Porter (J. R. Porter, Challenges to Editors of Scientific Journals, Science, 1963, 141, 1014-1017) and Estes (W. K. Estes, Editorial Note, J. comp. physiol. Psychol., 1964, 57, 1-2) and ask what useful purpose will be served by publishing the article. Substantial effort should then be devoted to organizing the paper in as concise but clear a manner as possible.

Authors are requested to consult the Publication Manual of the American Psychological Association for detailed instructions concerning manuscript format, preparation of tables and figures, etc.; the conventions of the American Institute of Physics are followed for abbreviation of physical units. When in doubt, examine a recent issue of the Journal.

All manuscripts should be submitted in duplicate to the Editor, Joseph B. Sidowski, accompanied by a short abstract. Original copy should be typed; drawings and photos must be of reproducible quality.

Descriptions of methods should be sufficiently detailed to allow replication. Contributors describing instruments or circuits are expected to supply specific listings of parts and components.

In the interest of speed of communication, time for processing manuscripts will be minimal. Publication in most instances should not exceed 6-16 weeks. All papers submitted will be acknowledged upon receipt and forwarded to two or more outside reviewers for evaluation.

Acknowledgements to reviewers other than those listed as consulting editors will be printed periodically. 